\title{
Enhanced Catalytic Activity Induced by the Nanostructuring Effect in Pd Decoration onto Doped Ceria Enabling an Origami Paper Analytical Device for High Performance of Amyloid- $\beta$ Bioassay
}

Kang Cui ${ }^{\mathrm{a}}$, Chenxi Zhou ${ }^{\mathrm{a}}$, Bowei Zhang ${ }^{\mathrm{b}}$, Lina Zhang ${ }^{\mathrm{d}}$, Yue Liu ${ }^{\mathrm{a}}$, Shiji Hao ${ }^{\mathrm{b}}$, Xiaohong Tang ${ }^{\mathrm{c}, *}$, Yizhong Huang ${ }^{\mathrm{b}, *}$, Jinghua $\mathrm{Yu}^{\mathrm{a}, *}$

${ }^{a}$ School of Chemistry and Chemical Engineering, University of Jinan, Jinan 250022, Shandong, P. R. China

${ }^{b}$ School of Materials Science and Engineering, Nanyang Technological University, Singapore 639798, Singapore.

c School of Electrical and Electronic Engineering, Nanyang Technological University, Singapore 639798, Singapore

${ }^{d}$ Shandong Provincial Key Laboratory of Preparation and Measurement of Building Materials, University of Jinan, Jinan, 250022, Shandong, P. R. China

* Corresponding authors.

E-mail address:

exhtang@ntu.edu.sg (X.Tang),yzhuang@ntu.edu.sg (Y. Huang),ujn.yujh@gmail.com (J.Yu). 


\section{Table of Contents}

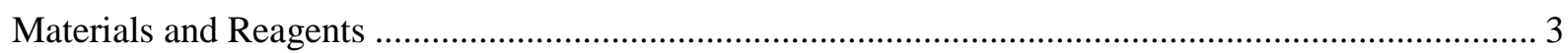

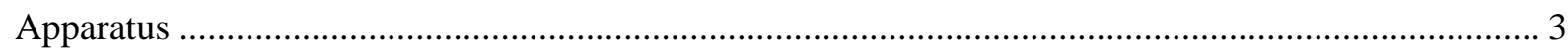

Fabrication of Au NPs Paper Work Electrode (Au-PWE) ................................................................. 3

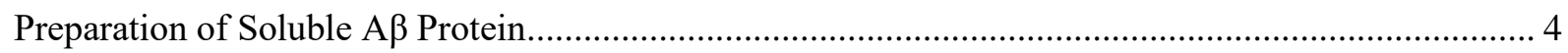

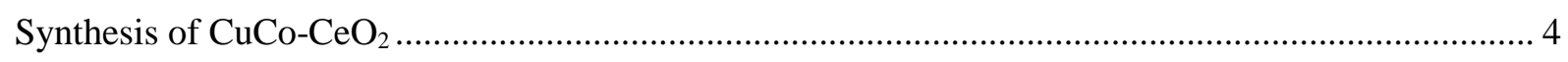

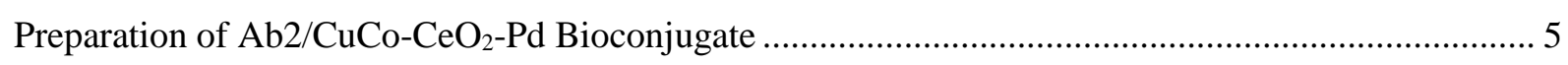

The Process of Origami Paper-Based Analytical Device (OPAD) Fabrication ....................................... 5

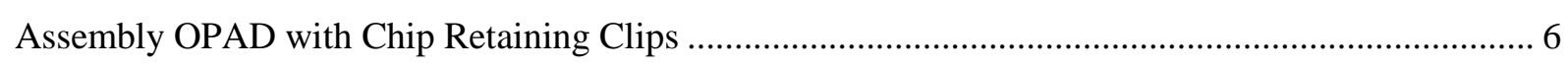

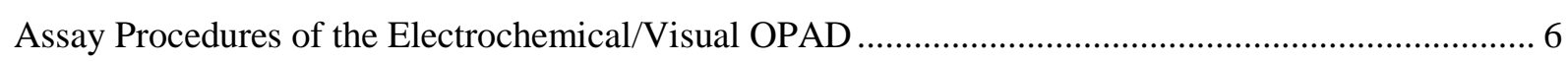

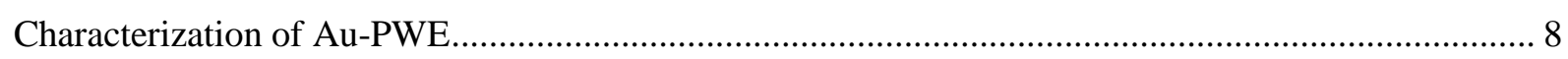

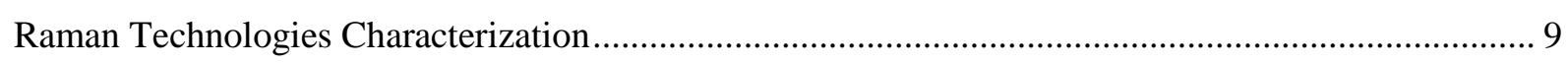

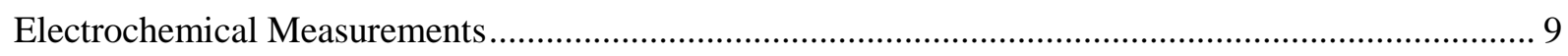

Characterization of the OPAD Modification Process.................................................................... 9

The Optimization of Experimental Conditions for the Proposed OPAD ............................................. 11

DPV Signals of OPAD with $\mathrm{CeO}_{2}, \mathrm{Co}-\mathrm{CeO}_{2}, \mathrm{Cu}-\mathrm{CeO}_{2}$, and $\mathrm{CuCo}-\mathrm{CeO}_{2}$, respectively $\ldots . . . . . . . . . . .11$

Colour Intensities of OPAD with $\mathrm{CeO}_{2}, \mathrm{Co}-\mathrm{CeO}_{2}, \mathrm{Cu}-\mathrm{CeO}_{2}, \mathrm{CuCo}-\mathrm{CeO}_{2}$, and $\mathrm{CuCo}-\mathrm{CeO}_{2}-\mathrm{Pd}$, respectively....................................................................... 11

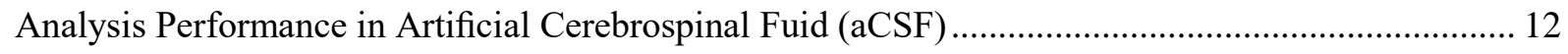

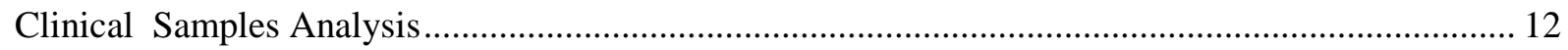

Comparison of the Proposed OPAD with Different Nanomaterials.....................................................16

Comparison of the Proposed OPAD with Other Techniques .......................................................... 17

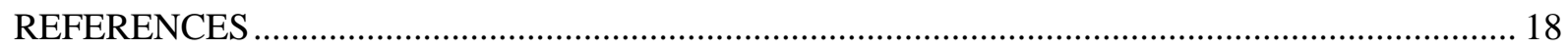




\section{Materials and Reagents}

$\mathrm{Ce}\left(\mathrm{NO}_{3}\right)_{3} \cdot 6 \mathrm{H}_{2} \mathrm{O}$ and $\mathrm{Na}_{2} \mathrm{PdCl}_{4}(99.99 \%)$ were purchased from Sigma-Aldrich Corporation (Shanghai, China). Polyvinylpyrrolidone (PVP), ethylene glycol (EG) and $\mathrm{H}_{2} \mathrm{O}_{2}$ were purchased from Tianjin Kemiou Chemical Reagent Company (Tianjin, China). $\mathrm{CuCl}_{2} \cdot 2 \mathrm{H}_{2} \mathrm{O}$ and $\mathrm{CoCl}_{2} \cdot 6 \mathrm{H}_{2} \mathrm{O}$ was purchased from AlfaAesar Corporation (Tianjin, China). 3,3',5,5'-tetramethylbenzidine (TMB) and acetic acid were obtained from Shanghai Jizhi Biochemical Technology Co., Ltd. (Shanghai, China). The bovine serum albumin (BSA) was obtained from Sangon Biotech (Shanghai, China) Co., Ltd. The antibody (Ab1, Ab2) of amyloid- $\beta$ protein $(A \beta)$ and $A \beta$ protein were obtained from Nanjing GenScript (Nanjing, China) Co., Ltd. China. The carcinoembryonic antigen (CEA), human immunoglobulin (IgG) and $\alpha$-synuclein were provided by Sangon Biotech (Shanghai, China) Co., Ltd. The artificial cerebrospinal fluid was purchased from Kingmorn Biotechnology Co., Ltd (Shanghai, China). All chemicals are used without further purification. Whatman chromatography paper No. $2(58.0 \mathrm{~cm}$ x $68.0 \mathrm{~cm})$ was purchased from GE Healthcare Worldwide (Shanghai, China), and was converted to A4 paper size for further development.

\section{Apparatus}

Cyclic voltammetry (CV), differential pulse voltammetry (DPV), and electrochemical impedance spectroscopy (EIS) were performed on CHI 760D electrochemical workstation (Chenhua Instruments Inc., Shanghai of China). Scanning electron microscopy (SEM) images were recorded on a JEOL JSM-5510 scanning electron microscope (JEOL, Japan). And the microscope was equipped with an Oxford X-MAX50 energy dispersive spectrometer (EDS) (Oxford, Britain). The JEOL 4000 EX microscope were operated to record the transmission electron microscopy (TEM) images. The Raman spectrum was recorded by Labram HR evolution spectrometer (Horiba jobin yvon Corporation, French). X-ray diffraction (XRD) patterns were collected on a Pa D8 advance diffractometer system equipped with $\mathrm{Cu}$ Kradiation (Bruker Co., Germany). X-ray photoelectron spectroscopy (XPS) measurement was performed by using a Thermo Fisher ESCALAB 250 X-ray photoelectron spectrometer. The three-electrode system, including the working electrode, the reference electrode, and the counter electrode, are from our laboratory.

\section{Fabrication of Au NPs Paper Work Electrode (Au-PWE)}

To achieve an expected signal read out amplification, the conduction of the paper substrate was strongly improved by in situ growth of Au NPs onto the cellulose fibers of 
detection area. In detail, the gold seed solution was firstly prepared based on the available strategies in our laboratory. Briefly, a three-necked flask with $80 \mathrm{~mL}$ of deionized water was heated to $90{ }^{\circ} \mathrm{C}$. And then $0.8 \mathrm{~mL}$ of $1 \% \mathrm{HAuCl}_{4}$ solution was added and heated to $95{ }^{\circ} \mathrm{C}$ for $5 \mathrm{~min}$. After that, $2.8 \mathrm{~mL}$ of $1 \%$ trisodium citrate was added into the flask with stirring for 15 min. Finally the prepared gold seed solution was kept to stir till cool down to room temperature and stored at $4{ }^{\circ} \mathrm{C}$ for future use. Once the gold seed was ready, $20 \mu \mathrm{L}$ of it was dropped into the detection area of oPAD, and equilibrated it for $1 \mathrm{~h}$ at room temperature with three times repeating to optimize the modification of Au NPs seeds on cellulose fibers. Subsequently, $25 \mu \mathrm{L} 1 \% \mathrm{HAuCl}_{4}$ with $25 \mu \mathrm{L}$ of $0.1 \mathrm{M} \mathrm{AA}$ freshly mixed growth solution was immediately added into the as-prepared Au NPs seed modified paper electrode for incubating at room temperature for $2 \mathrm{~h}$. After thoroughly washing the obtained Au NPs paper work electrode (Au-PWE) with deionized water, an urchin-like Au NPs layer covered onto cellulose fibers with good conductivity was achieved, and dried $20 \mathrm{~min}$ at room temperature for further utilization. On account of the inherit merit of chromatography paper and the convincing conductivity of gold, the developed Au-PWE with larger surface area compared with bare PWE was proposed to fabricate lab-on-paper device for higher sensitive A $\beta$ detection.

\section{Preparation of Soluble A $\beta$ Protein}

The preparation of soluble $\mathrm{A} \beta$ protein was operated based on the previous investigations with minor modifications ${ }^{1-3}$. In brief, the $A \beta$ protein was firstly achieved by dissolving lyophilized $\mathrm{A} \beta$ peptide into 1,1,1,3,3,3-hexafluoro-2-propanol with sonication of $10 \mathrm{~min}$. The obtained products were then reconstituted into $20 \mathrm{mM} \mathrm{NaOH}$ solution with a resulting concentration of $2 \mathrm{mM}$. By diluting with PBS (10 mM, pH 2.0) to getting a final concentration of $50 \mu \mathrm{M}$, the sample was further prepared with PBS (2 mM, pH 7.2) dilution to the desired concentration for the further experiments at $25{ }^{\circ} \mathrm{C}$. A centrifugation process at $14000 \mathrm{rpm}$.

\section{Synthesis of $\mathrm{CuCo}-\mathrm{CeO}_{2}$}

In order to achieve the $\mathrm{CuCo}-\mathrm{CeO}_{2}-\mathrm{Pd}$ nanospheres, the synthesis of $\mathrm{CuCo}-\mathrm{CeO}_{2}$ composites were firstly operated based on the previous literatures with a minor modification ${ }^{4}$. Briefly, $500 \mathrm{mg} \mathrm{Ce}\left(\mathrm{NO}_{3}\right)_{3} \cdot 6 \mathrm{H}_{2} \mathrm{O}$ and $200 \mathrm{mg}$ polyvinylpyrrolidone (PVP) were firstly dissolved in $14 \mathrm{~mL}$ ethylene glycol (EG) under stirring for $30 \mathrm{~min}$ at room temperature. After dropping $0.5 \mathrm{~mL} 20 \mathrm{mg} / \mathrm{mL}$ of $\mathrm{CuCl}_{2} \cdot 2 \mathrm{H}_{2} \mathrm{O}$ and $0.5 \mathrm{~mL}$ of $\mathrm{CoCl}_{2} \cdot 6 \mathrm{H}_{2} \mathrm{O}$ solutions into the 
above mixture, the mixture solution was transferred into a $20 \mathrm{~mL}$ capacity of teflon-lined autoclave and heated up to $160{ }^{\circ} \mathrm{C}$ for reaction $8 \mathrm{~h}$. Once the reaction was finished, the autoclave was brought out for natural cooling at room temperature. Then the obtained products were collected, and rinsed with deionized water and absolute alcohol respectively for several times. Ultimately, the collected products were dried at $60{ }^{\circ} \mathrm{C}$ overnight with a final calcination at $300{ }^{\circ} \mathrm{C}$ at $1{ }^{\circ} \mathrm{C} / \mathrm{min}$ for $1 \mathrm{~h}$, labeling as $\mathrm{CuCo}-\mathrm{CeO}_{2}$.

\section{Preparation of $\mathrm{Ab2} / \mathrm{CuCo}-\mathrm{CeO}_{2}-\mathrm{Pd}$ Bioconjugate}

As shown in the Scheme $1 \mathrm{~A}$, the preparation of $\mathrm{Ab} 2-\mathrm{CuCo}-\mathrm{CeO}_{2}-\mathrm{Pd}$ bioconjugate is illustrated. After achieved $\mathrm{CuCo}-\mathrm{CeO}_{2}-\mathrm{Pd}$ nanospheres, $1.0 \mathrm{mg}$ of $\mathrm{CuCo}-\mathrm{CeO}_{2}-\mathrm{Pd}$ were firstly dispersed into $250 \mu \mathrm{L}$ of $\mathrm{pH}$ 7.0 PBS solution, and then transferred to the solution of $250 \mu \mathrm{L}$ of $1.0 \mu \mathrm{g} \mathrm{mL}^{-1} \mathrm{Ab} 2$ for incubating at $4{ }^{\circ} \mathrm{C}$ for $24 \mathrm{~h}$. Then, the prepared $\mathrm{Ab} 2 / \mathrm{CuCo}-\mathrm{CeO}_{2}-\mathrm{Pd}$ bioconjugates were collected by centrifugation, and further washed with the PBS solution of $\mathrm{pH}$ 7.0. In order to block the surface nonspecific active sites, once gained the $\mathrm{Ab} 2 / \mathrm{CuCo}-$ $\mathrm{CeO}_{2}$-Pd bioconjugate, $150 \mu \mathrm{L}$ of $1.0 \%$ bovine serum albumin (BSA) was added to the obtained products and vibrated at $4{ }^{\circ} \mathrm{C}$ for $3 \mathrm{~h}$, and then washed away the extra BSA with $\mathrm{pH}$ 7.0 PBS solution. The prepared bioconjugates were then stored at $\mathrm{pH} 7.0 \mathrm{PBS}$ solution for the further experiments at $4{ }^{\circ} \mathrm{C}$.

\section{The Process of Origami Paper-Based Analytical Device (OPAD) Fabrication}

Concretely, when the black guide line on manageable-cleaning tab (purple color) was firstly aligned with the edge line of the folded electrochemical and colorimetric detection tab at the initial position, the detection area could be reasonably located on the wax printed area on the manageable-cleaning tab with its hydrophobic property. In this case, the buffer solution containing biochemical reagents could be prohibited from infiltrating into the neighboring layers, which could further ensure biochemical reagents for storing in the essential incubation

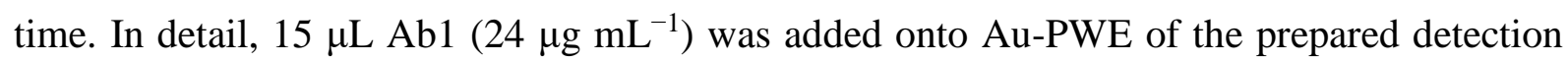
area and incubated at $4{ }^{\circ} \mathrm{C}$ for $12 \mathrm{~h}$. Then, by slickly shifting thumb control to the neighboring black guide line, the folded electrochemical and colorimetric detection tab could be exactly relocated to the washing area on the manageable-cleaning tab with its hydrophilic property. In this case, the buffer solution containing biochemical reagents could infiltrate into the neighboring bottom layer, leading to the buffer solution containing physically adsorbed biochemical reagents flowing to waste pool via capillary function along with the well-defined channel on the manageable-cleaning tab. In detail, pH 7.0 PBS solution was operated to rinse 
the incubated Ab1-Au-PWE for three times to remove the unbound Ab1 reagents which could be immediately brought to the waste pool of paper slip as the waste liquid due to the capillary attraction. Based on this kind of design and operation, the hydrophobicity and hydrophilicity conversion procedure of cellulose paper and the manageable-cleaning treatment could allowed the reagents, such as $\mathrm{BSA}$ and $\mathrm{Ab} 2 / \mathrm{CuCo}-\mathrm{CeO}_{2}-\mathrm{Pd}$ bioconjugates to be successfully immobilized onto the detection area in the following fabrication process of oPAD, which is significant for designing and fabricating portable paper-based analytical devices. After accomplishment of design and fabrication of oPAD, the operation of oPAD was conducted to fully examine the performance.

\section{Assembly OPAD with Chip Retaining Clips}

After the defined size and specific pattern of paper was designed with Adobe illustrator CS6 software, it was then printed onto No. 2 Whatman chromatography paper with a wax printer and later placed the obtained paper sheet into an oven for $50 \mathrm{~s}$ at $130{ }^{\circ} \mathrm{C}$ to melt the wax. In this way, the melted wax could penetrated into the cellulose fibers for forming a three-dimensional hydrophobic wall due to its inherent porous structure of paper. By the curing procedure, the unprinted cellulose paper area could still keep its intrinsic properties, such as flexibility, hydrophilicity and porous structure. With this method, the various function area were able to be spatially separated so as to control the fluid connection for realizing detection area modifications in the electrochemical signal amplification read out system and the further electrode screen printing process. Based on the screen printing techniques, graphite ink and $\mathrm{Ag} / \mathrm{AgCl}$ paste were developed to print working, counter and reference electrodes on the corresponding unprinted paper fibers of circles zone. To finally accomplish the assembly of the three-dimensional structure of oPAD, a razor was used to cut the printed paper sheet to different single tabs and then folded the individual tabs along the connecting space between two items. Figure 1B presents the photographs of the constructed oPAD assembled with chip retaining clips.

\section{Assay Procedures of the Electrochemical/Visual OPAD}

The analytical procedure of the oPAD with effectively manageable-cleaning of paperbased implement for achieving dual mode electrochemical/visual analysis of $\mathrm{A} \beta$ was demonstrated in Figure S1. The mainly produces are shown as following: 
(i) In order to assemble the three-dimensional OPAD, the printed paper chips were folded, as shown in Figure S1A. Details are shown below: first, the working electrode slip was folded down to cover the reference electrode and the counter electrode slip. Then, a three-electrode system could be constructed for the measurement of the electrochemical signal. Afterwards, the folded slip part was further bended along the pre-configured connecting space between two items. Finally, the colorimetric detection slip was further folded down and placed onto the bottom label of the electrochemical and colorimetric detection tab. The folded paper chip can be reasonably utilized for visual detection too.

(ii) To achieve the sensitive electrochemical signal read out, the paper chip modification was operated, , as illustrated in Figure S1B. Firstly, $25 \mu \mathrm{L} \mathrm{Ab1}\left(24 \mu \mathrm{g} \mathrm{m}^{-1}\right)$ was added onto the Au NPs paper work electrode (Au-PWE), where urchin-like Au NPs layer were in situ functionalized onto the cellulose fibers of detection area, and incubated at $4{ }^{\circ} \mathrm{C}$ for $12 \mathrm{~h}$. After sufficient rinsing of PBS solution ( $\mathrm{pH}$ 7.0) for three times, the generated Ab1 immobilized Au-PWE (Ab1/Au-PWE) was blocked with $25 \mu \mathrm{L}$ of $2.0 \%$ bovine serum albumin (BSA) at room temperature for $2 \mathrm{~h}$ and form BSA/ Ab1/Au-PWE. Afterwards, the prepared BSA/Ab1/Au-PWE was washed with $\mathrm{pH}$ 7.0 PBS solution to remove the non-specific adsorption BSA. Subsequently, the pre-prepared Ab2-CuCo- $\mathrm{CeO}_{2}-\mathrm{Pd}$ bioconjugates with the unique catalytic properties of $\mathrm{CuCo}-\mathrm{CeO}_{2}-\mathrm{Pd}$ nanospheres were introduced onto BSA/Ab1/Au-PWE through specific interaction of antigen-antibody. After that, the obtained $\mathrm{Ab} 2-\mathrm{CuCo}-\mathrm{CeO}_{2}-\mathrm{Pd} / \mathrm{BSA} / \mathrm{Ab} 1 / \mathrm{Au}-\mathrm{PWE}$ of detection area was gently rinsed with PBS ( $\mathrm{pH} 7.0$ ) to remove unbound $\mathrm{Ab} 2-\mathrm{CuCo}-\mathrm{CeO}_{2}-\mathrm{Pd}$ bioconjugates. Finally, the quantitative criteria of electrochemical detection for $A \beta$ would be operated in PBS (pH 7.0) in the presence of $5.0 \mathrm{mM} \mathrm{H}_{2} \mathrm{O}_{2}$.

(iii) In order to efficiently immobilize the functional items, such as, Ab1, BSA and Ab2$\mathrm{CuCo}-\mathrm{CeO}_{2}-\mathrm{Pd}$ bioconjugates onto $\mathrm{Au}-\mathrm{PWE}$ and simplify the operating procedure for achieving fast detection for the oPAD fabrication, a manageable-cleaning tab featured with hydrophilic-hydrophobic adjustable cleaning operation was designed, as illustrated in Figure S1C. Besides, the mixture solution of $20 \mu \mathrm{L}$ TMB $(20 \mathrm{mM})$ and $20 \mu \mathrm{L}$ acetic acid $(\mathrm{pH} 4.5)$ were pre-embedded into the color development area for the further colorimetric detection.

(iv) When the functional processes with cleaning operation were completed step by step, the manageable-cleaning tab was removed. And then, $100 \mu \mathrm{L}$ of PBS solution (pH 7.0) with glucose $(10 \mathrm{mM})$ and $\mathrm{GOx}\left(0.5 \mathrm{mg} \cdot \mathrm{mL}^{-1}\right)$, which were previously prepared with 
incubation time $1 \mathrm{~h}$ at $37{ }^{\circ} \mathrm{C}$, was dropped onto the detection area as an electrochemical microcell for electrochemical detection (Figure S1D).

(v) Finally, for the colorimetric detection, the paper slip with color development area and contrast area were overlapped with the folded electrochemical detection slip so as to contact them each other. $100 \mu \mathrm{L}$ PBS $(\mathrm{pH} 7.0,0.1 \mathrm{M})$ was added onto the color development area into which $25 \mu \mathrm{L}$ of TMB $(20 \mathrm{mM})$ and $25 \mu \mathrm{L}$ of acetic acid (pH 4.5) were pre-embedded. In this case, the produced $\mathrm{H}_{2} \mathrm{O}_{2}$ caused by the oxidation of glucose catalyzed by $\mathrm{CuCo}-\mathrm{CeO}_{2}-\mathrm{Pd}$ nanospheres could be conducted through the hydrophilic cellulose fibers of the channel and reacted with the pre-embedded TMB in the color development area to eventually realize the visual signal read out and realize the dualmode electrochemical/visual detecting $\mathrm{A} \beta$ on oPAD platform (Figure $\mathrm{S} 1 \mathrm{E}$ ).

During the assay procedures of the electrochemical/visual oPAD, razors and chip retaining clips were used to accomplish the assembly of the three-dimensiona oPAD. Figure 1B presents the photographs of the constructed oPAD objects: the physical picture of unfolded oPAD (a); The assembled oPAD (b); oPAD folding during the process of electrode modification and the process of electrode manageable-cleaning (c) and (d).

\section{Characterization of Au-PWE}

The SEM images of Figure S2 presents the morphological characterization of Au-PWE and PWE. As shown in the Figure S2A, the porous architecture and rough surface of the bare paper fibers could be found, which was suitable for the substrate material in the fabrication of bioassay device with its advantages such as, effective functionality and good flexibility and easy facilitating the chemical transports. In order to achieve the optimal performance of oPAD, in situ growth of Au NPs onto cellulose fibers strategy was adopted to improve the conductivity of paper substrate. Figure S2B shows the urchin-like Au NPs with a size of about 100-250 nm appeared onto the cellulose paper. The Au NPs with plenty of spikes developed throughout the paper substrate would be beneficial to immobilize biochemical reagents and transport ions and electrons metal on account of their electrochemically active sites, facilitating to build a proper microenvironment for bioassay of A $\beta$. The inset SEM image in Figure S2B presented the corresponding energy-dispersive-X-ray-spectroscopy (EDS) analysis, which confirms that the urchin-like Au NPs layer was successfully functionalized onto the surface of paper substrate with Au element peak exist. Figure S2C further shows the zoom in SEM image of urchin-like Au NPs immobilization onto the paper substrate, where 
the clearly urchin-like Au NPs with plenty of spikes could be easily found, which definitely improved the electrical conductivity of the paper substrate.

\section{Raman Technologies Characterization}

To further support the successful synthesis of $\mathrm{CuCo}-\mathrm{CeO}_{2}-\mathrm{Pd}$ nanocomposites, Raman technologies were applied to characterize the $\mathrm{CeO}_{2}, \mathrm{Cu}-\mathrm{CeO}_{2}, \mathrm{Co}-\mathrm{CeO}_{2}, \mathrm{CuCo}-\mathrm{CeO}$ and $\mathrm{CuCo}-\mathrm{CeO}_{2}-\mathrm{Pd}$ materials, As shown in Figure $3 \mathrm{~A}$, the as-synthesized $\mathrm{CuCo}-\mathrm{CeO}_{2}-\mathrm{Pd}$ nanocomposites possess a similar Raman spectra with $\mathrm{CeO}_{2}$ in $200-800 \mathrm{~cm}^{-1}$ range. Typically, for $\mathrm{CeO}_{2}$ sample, a main Raman band about $462 \mathrm{~cm}^{-1}$ can be observed, which is related to the vibrational mode of $\mathrm{CeO}_{2}$ fluorite-structured materials (black curve) ${ }^{5,6}$. For the $\mathrm{CuCo}-\mathrm{CeO}_{2}-$ $\mathrm{Pd}$ sample, the band ascribed to the vibrational mode of $\mathrm{CeO}_{2}$ shifts to lower frequency at about $454 \mathrm{~cm}^{-1}$ with a slight increase of the peak width, which indicates the formation of defects in the lattice structure of the $\mathrm{CeO}_{2}$ with the occurrence of doping elements, confirming the successfully synthesis of $\mathrm{CuCo}-\mathrm{CeO}_{2}-\mathrm{Pd}$ (red curve) ${ }^{6,7}$. Apart from this, several bands at 291,360 , and $595 \mathrm{~cm}^{-1}$ are found, which can be ascribed to the formation of a high amount of oxygen vacancies in the $\mathrm{CeO}_{2}$ structure with the codoping of metal pieces into it ${ }^{8}$.

\section{Electrochemical Measurements}

Electrochemical experiments were operated with a standard three-electrode system which was integrated on oPAD, as shown in Figure 4 and 5. DPV signal were recorded in 200 $\mu \mathrm{L}$ PBS $(\mathrm{pH} 7.0,0.1 \mathrm{M})$ at room temperature with a $10 \mathrm{mM}$ concentration of glucose. The parameters of DPV were $50 \mathrm{mV} / \mathrm{s}$ sweeping rate with a $50 \mathrm{~ms}$ pulse width, $0.2 \mathrm{~s}$ pulse period, and a voltage range from $100 \mathrm{mV}$ to $800 \mathrm{mV}$ (vs. $\mathrm{Ag} / \mathrm{AgCl}$ ). CV and EIS were conducted in $1.0 \mathrm{~mL}$ of $5 \mathrm{mM} \mathrm{Fe}(\mathrm{CN})_{6}^{3-/ 4-}$ as the redox probe. $\mathrm{CV}$ measurements were conducted at a 50 $\mathrm{mV} / \mathrm{s}$ scan rate with the potential from $100 \mathrm{mV}$ to $800 \mathrm{mV}$ (vs. $\mathrm{Ag} / \mathrm{AgCl}$ ). And the EIS signals were measured at a frequency range of 101 to $105 \mathrm{~Hz}$ with an excitation signal of 5 $\mathrm{mV}$, and a formal potential of $220 \mathrm{mV}$ (vs. $\mathrm{Ag} / \mathrm{AgCl}$ ). The impedance ( $\mathrm{Z}$ ) of electron transfer in the EIS signal was contributed with its real $(\mathrm{Z}$ re) and imaginary $(\mathrm{Z}$ im) components.

\section{Characterization of the OPAD Modification Process}

$\mathrm{CV}$ is normally utilized as a facilely but powerfully electrochemical technique to investigate the construction of electrochemical biosensors step by step. Here, the CV measurements were carried out at the $0.1 \mathrm{M}$ PBS ( $\mathrm{pH}$ 7.0) containing $0.1 \mathrm{M} \mathrm{KCl}$ and $5.0 \mathrm{mM}$

$\left[\mathrm{Fe}(\mathrm{CN})_{6}\right]^{3-/ 4-}$. As we could see from Figure 4A, compared to bare PWE (curve a) displaying 
a pair of defined redox peaks, the redox current of Au-PWE (curve b) was significantly increased, illustrating the urchin-like AuNP layer could enhance the PWE effective area and increased the electron transfer rate. When Ab1 was introduced, the decreased redox peak current of Ab1/Au-PWE (curve c) was found, indicating that Ab1 could hinder the electrons conduction from the bulk solution to the Au-PWE surface. With the incubation with BSA, the peak current of BSA/Ab1/Au-PWE further decreased (curve d). As soon as the A $\beta$ antigen was captured onto the surface of electrode, the peak current of the $A \beta / \mathrm{BSA} / \mathrm{Ab} 1 / \mathrm{Au}-\mathrm{PWE}$ was decrease more due to the enhanced steric hindrance of Ab2 onto BSA/Ab1/Au-PWE, indicating that $A \beta$ antigen was successfully bind onto the surface of Ab1 immobilized electrode (curve e). Consequently, in view of the above results, the construction process of the biosensor was successfully achieved.

EIS, as a powerful and non-destructive technique, is generally utilized to characterize surface changes at the solid-liquid interface. With the application of AC potentials to the electrode surface, the frequency dependence of the impedance could reveal underlying chemical processes, where the semicircle diameter at higher frequencies responses to the electron transfer resistance $\left(R_{\mathrm{et}}\right)$ while the linear part at lower frequencies responses to the diffusion process. Figure 4B displayed results of the EIS experiments which is operated in the PBS (0.1 M, pH 7.0) with $0.1 \mathrm{M} \mathrm{KCl}$ and $5.0 \mathrm{mM}\left[\mathrm{Fe}(\mathrm{CN})_{6}\right]^{3-/ 4-}$. It can be observed that the bare PWE showed a small semicircle (curve a). After in situ growth of urchin-like AuNPs onto the cellulose fibers, the EIS of the Au-PWE exhibited the smallest semicircle with a lowest $R_{\text {et }}$ (curve b) due to the outstanding conductivity of urchin-like AuNPs. After the Ab1 was immobilized onto the surface of Au-PWE, the $R_{\text {et }}$ of Ab1/Au-PWE increased (curve c) because the assembled biological molecules could block the ferricyanide diffusion towards the surface of Au-PWE. BSA, as a blockers, was further developed to bind nonspecific binding sites of Au-PWE, which results in a apparent increase in $R_{\text {et }}$ (curve d). When the obtained BSA/Ab1/Au-PWE was incubated with A $\beta$ protein solution, the $R_{\text {et }}$ of $\mathrm{A} \beta / \mathrm{BSA} / \mathrm{Ab} 1 / \mathrm{Au}-\mathrm{PWE}$ evidently increased (curve e), eventually demonstrating the successful fictionalization of target $\mathrm{A} \beta$ protein. The increased $R_{\mathrm{et}}$ might result from the steric hindrance of immobilized proteins, which could impede the $\left[\mathrm{Fe}(\mathrm{CN})_{6}\right]^{3-/ 4-}$ redox probes accessing to the surface of the Au-PWE. As a result, the stepwise increasement of the $R_{\text {et }}$ confirmed the successful construction of oPAD immunosensor interface. And the $R_{\text {et }}$ conclusions are in accordance with that of the $\mathrm{CV}$ experiments results, further indicating that the oPAD sensing platform was successfully assembly. 


\section{The Optimization of Experimental Conditions for the Proposed OPAD}

In order to receive the improved performance of the proposed electrochemical/visual oPAD, the optimized experimental conditions for the quantitative behavior of oPAD were investigated. Firstly, since the signal amplification of the oPAD was directly correlated to the concentration of glucose, the concentration of glucose in $2 \mathrm{~mL}$ of PBS (0.1 M, pH 7.0) was tested from $0 \mathrm{mM}$ to $20 \mathrm{mM}$. As shown in Figure S4A, catalytic peak current resulting from glucose oxidation measured at the voltage of $0.33 \mathrm{~V}$ increased as the glucose concentration increased from 0 to $10.0 \mathrm{mM}$, and then the current of oxidation peak remained constant. Consequently, $10.0 \mathrm{mM}$ was used as the experimental concentration of glucose.

Similarly, the proper environment of $\mathrm{pH}$ of PBS was crucial for the performance of the proposed oPAD. As shown in Figure S4B, the adaptability of the oPAD in the various $\mathrm{pH}$ values were investigated. At the neutrally experimental condition with $\mathrm{pH} 7.0$, the fabricated oPAD presented a higher oxidation current for the glucose oxidation measurements, and was selected for the further study.

\section{DPV Signals of OPAD with $\mathrm{CeO}_{2}, \mathrm{Co}-\mathrm{CeO}_{2}, \mathrm{Cu}-\mathrm{CeO}_{2}$, and $\mathrm{CuCo}-\mathrm{CeO}_{2}$, respectively.}

Furthermore, DPV signals of different sensors via $\mathrm{CeO}_{2}, \mathrm{Co}-\mathrm{CeO}_{2}, \mathrm{Cu}-\mathrm{CeO}_{2}$, and $\mathrm{CuCo}-$ $\mathrm{CeO}_{2}$ were investigated under the same conditions and the results were shown in Figure S5. It could be seen from the experimental results that the doping of $\mathrm{Cu} / \mathrm{Co}$ and $\mathrm{Pd}$ elements could improve the morphology uniformity of $\mathrm{CeO}_{2}$ nanomaterials and increase its catalytic activity with the successfully generated abundant oxygen vacancies, so that the oPAD via CuCo$\mathrm{CeO}_{2}-\mathrm{Pd}$ achieved high sensitivity with the wide linear range and the low detection limit compared with that of pure $\mathrm{CeO}_{2}$ or $\mathrm{Cu} / \mathrm{Co}$-doped ones (Table $\mathrm{S} 1$ ), which further indicated the superior catalytic activity of the $\mathrm{CuCo}-\mathrm{CeO}_{2}-\mathrm{Pd}$.

\section{Colour Intensities of OPAD with $\mathrm{CeO}_{2}, \mathrm{Co}_{-} \mathrm{CeO}_{2}, \mathrm{Cu}-\mathrm{CeO}_{2}, \mathrm{CuCo}_{-} \mathrm{CeO}_{2}$, and $\mathrm{CuCo}-$ $\mathrm{CeO}_{2}-\mathrm{Pd}$, respectively.}

In order to further investigate the function of doping $\mathrm{Cu}$, $\mathrm{Co}$ and $\mathrm{Pd}$ elements into $\mathrm{CeO}_{2}$ matrix in the colorimetric system, the complementary supplemental experiment was performed on the color development of TMB with $\mathrm{CeO}_{2}, \mathrm{Co}-\mathrm{CeO}_{2}, \mathrm{Cu}-\mathrm{CeO}_{2}, \mathrm{CuCo}-\mathrm{CeO}_{2}$, and $\mathrm{CuCo}-\mathrm{CeO}_{2}-\mathrm{Pd}$, respectively. The experimental results were shown in Figure S6. From this figure, we could see that under the same target concentration conditions, the deeper color development results could be obtained by using $\mathrm{CuCo}-\mathrm{CeO}_{2}-\mathrm{Pd}$ as a catalyst instead of other 
nanomaterials. The reason for this phenomenon was that the doping of $\mathrm{Cu} / \mathrm{Co}$ and $\mathrm{Pd}$ could increase the content ratio of $\mathrm{Ce}^{3+} / \mathrm{Ce}^{4+}$ in $\mathrm{CeO}_{2}$. In the presence of $\mathrm{H}_{2} \mathrm{O}_{2}$, the circulation between $\mathrm{Ce}^{3+} / \mathrm{Ce}^{4+}$ could be enlarged, and in this process, $\mathrm{H}_{2} \mathrm{O}_{2}$ could generate more $\cdot \mathrm{OH}$ to participate in the colorimetric reaction of TMB.

\section{Analysis Performance in Artificial Cerebrospinal Fuid (aCSF)}

To evaluate the application of the proposed oPAD for clinical laboratory, the oPAD was firstly applied for $\mathrm{A} \beta$ concentration detection in aCSF. aCSF comprising $150 \mathrm{mM} \mathrm{NaCl}, 3.0$ $\mathrm{mM} \mathrm{KCl}, 1.4 \mathrm{mM} \mathrm{CaCl} 2,0.8 \mathrm{mM} \mathrm{MgCl} 2,1.0 \mathrm{mM}$ sodium phosphate and $3 \mu \mathrm{M}$ BSA was prepared in-house.

\section{Clinical Samples Analysis}

The clinical application value of the proposed $\mu \mathrm{PAD}$ was evaluated by testing on actual human serum. Particularly, the human serum was collected in a separation gel accelerating tube with repeated reversing and mixing evenly for three times. After the human serum had clogged completely (about $30 \mathrm{~min}$ ), the human serum collection tube was put in a centrifuge and centrifuged at $5000 \mathrm{rpm}$ for $5 \mathrm{~min}$ in a low-temperature chamber. Finally, the human serum was taken out with a pipette. Different concentrations of $\mathrm{A} \beta(5 \mathrm{pM}-50 \mathrm{nM})$ were incorporated into the purified human serum. As shown in Figure S7A, as the A $\beta$ concentration increased, the peak current signal gradually increased and reached a linear dynamic range equivalent to that of PBS buffer (5 pM-50 nM), which indicated that the method could be successfully used for the quantitative detection of $A \beta$ in human serum. The detection limit was estimated to be $1.35 \mathrm{pM}$, which was also comparable to the detection limit in the pure PBS assay. The linear range and detection limit of oPAD can meet the requirements of clinical diagnostic samples with low $A \beta$ concentrations because the concentration of $A \beta$ in the cerebrospinal fluid and human plasma is in the range of 5.5-195 $\mathrm{pM}^{9,10}$. Also, the DPV current response increased linearly with the logarithm of the A $\beta$ concentration (Figure S7B), and the regression equation was $I=0.63 \log c+11.78\left(R^{2}=0.981\right)$. 

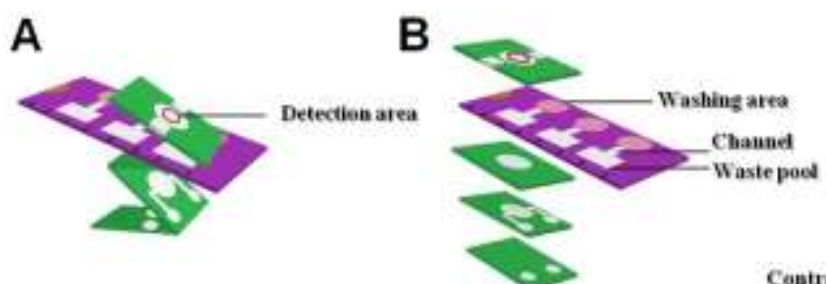

C

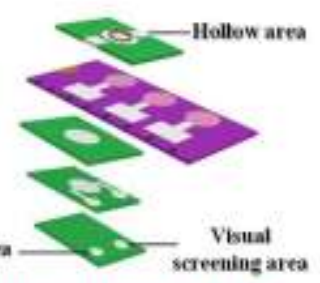

Folding device

Paper chip modification

Paper chip washing

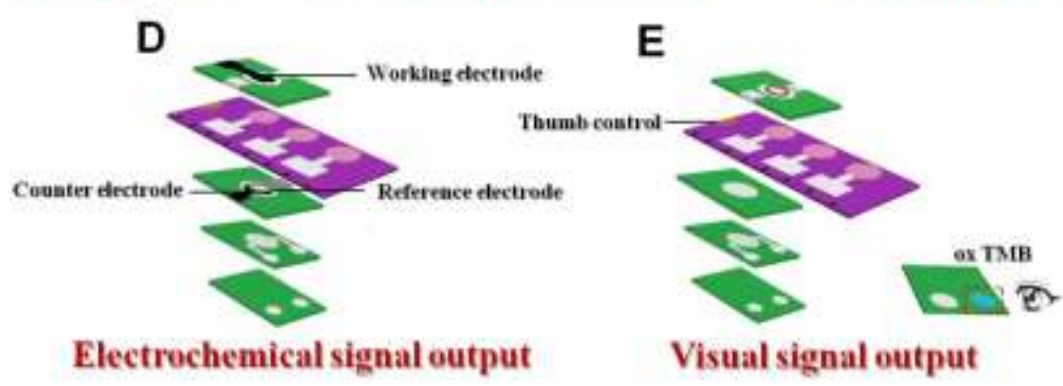

Figure S1. The corresponding the three-dimensional construction illustration for assay procedures of the electrochemical/visual oPAD. (A), (B) and (C): oPAD folding during the process of electrode modification and the process of electrode manageable-cleaning; (D) and (E): oPAD folding for the process of electrochemical/visual signal output.

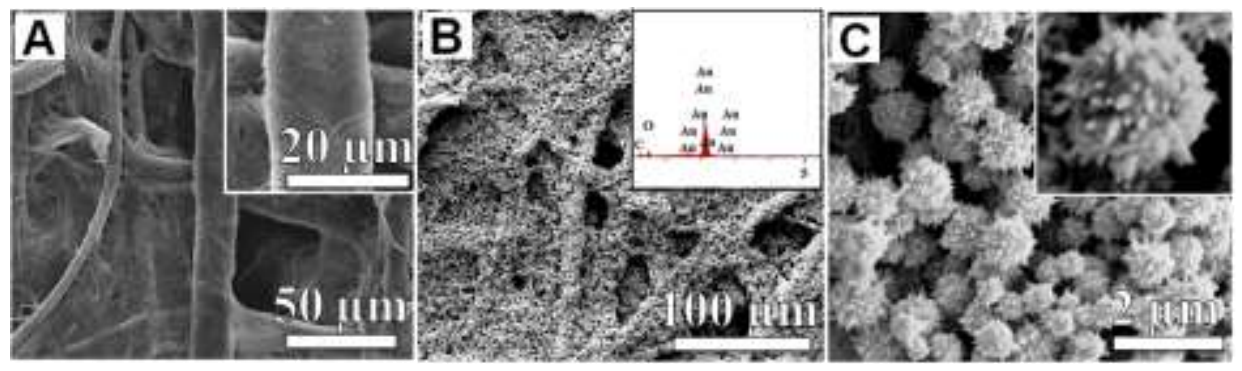

Figure S2. SEM images of the bare paper fibers (A); SEM images of the paper fibers functionalized with urchin-like Au NPs (B), and the corresponding EDS (inset of (B)); SEM images of the obtained urchin-like Au NPs on paper fibers with amplification (C). 

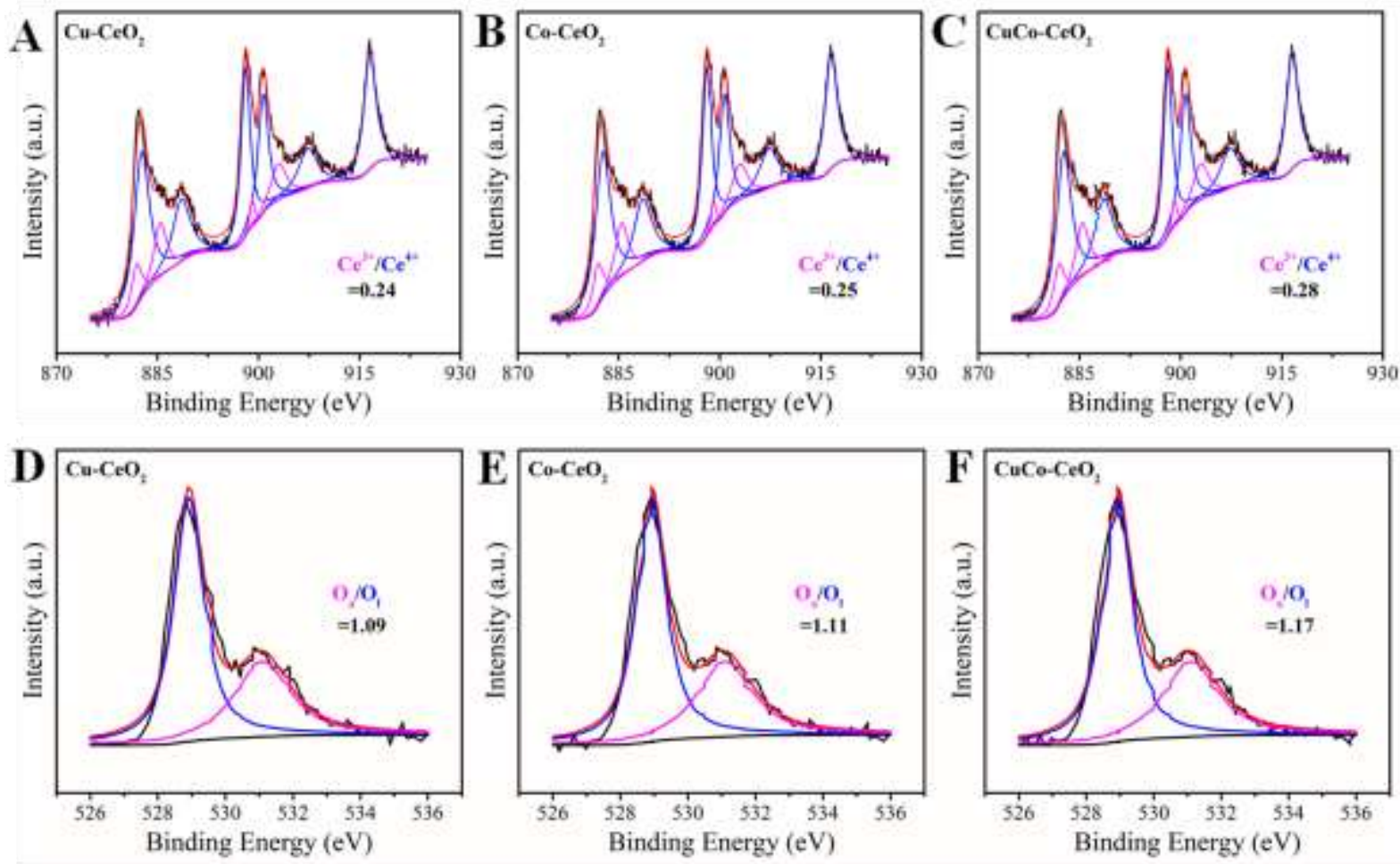

Figure S3. Ce $3 \mathrm{~d}$ XPS spectra of the $\mathrm{Cu}-\mathrm{CeO}_{2}(\mathrm{~A}), \mathrm{Co}-\mathrm{CeO}_{2}(\mathrm{~B})$ and $\mathrm{CuCo}-\mathrm{CeO}_{2}$ (C); O 1s XPS spectra of the $\mathrm{Cu}-\mathrm{CeO}_{2}(\mathrm{D}), \mathrm{Co}-\mathrm{CeO}_{2}(\mathrm{E})$ and $\mathrm{CuCo}-\mathrm{CeO}_{2}(\mathrm{~F})$.
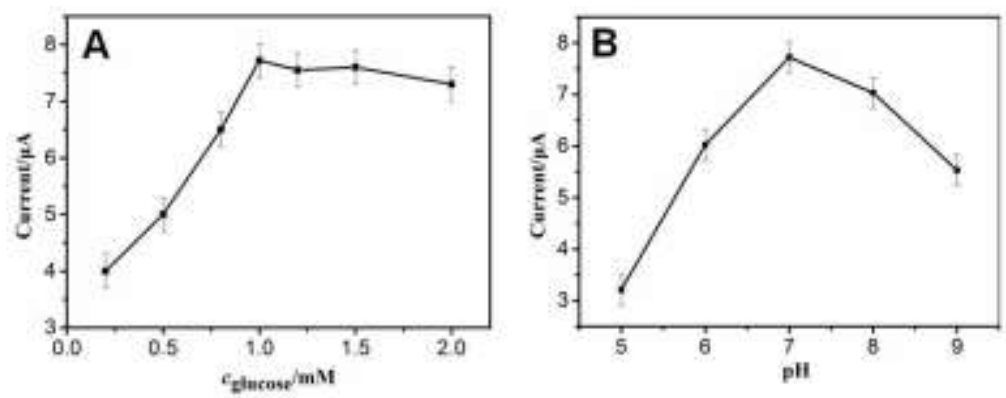

Figure S4. The effect of PH of the proposed oPAD performance (A); The effect of the glucose concentration for operating oPAD in $1.0 \mathrm{~mL}$ of PBS $(0.1 \mathrm{M}, \mathrm{pH} 7.0)$ from $0 \mathrm{mM}$ to $20 \mathrm{mM}(\mathrm{B})$. 

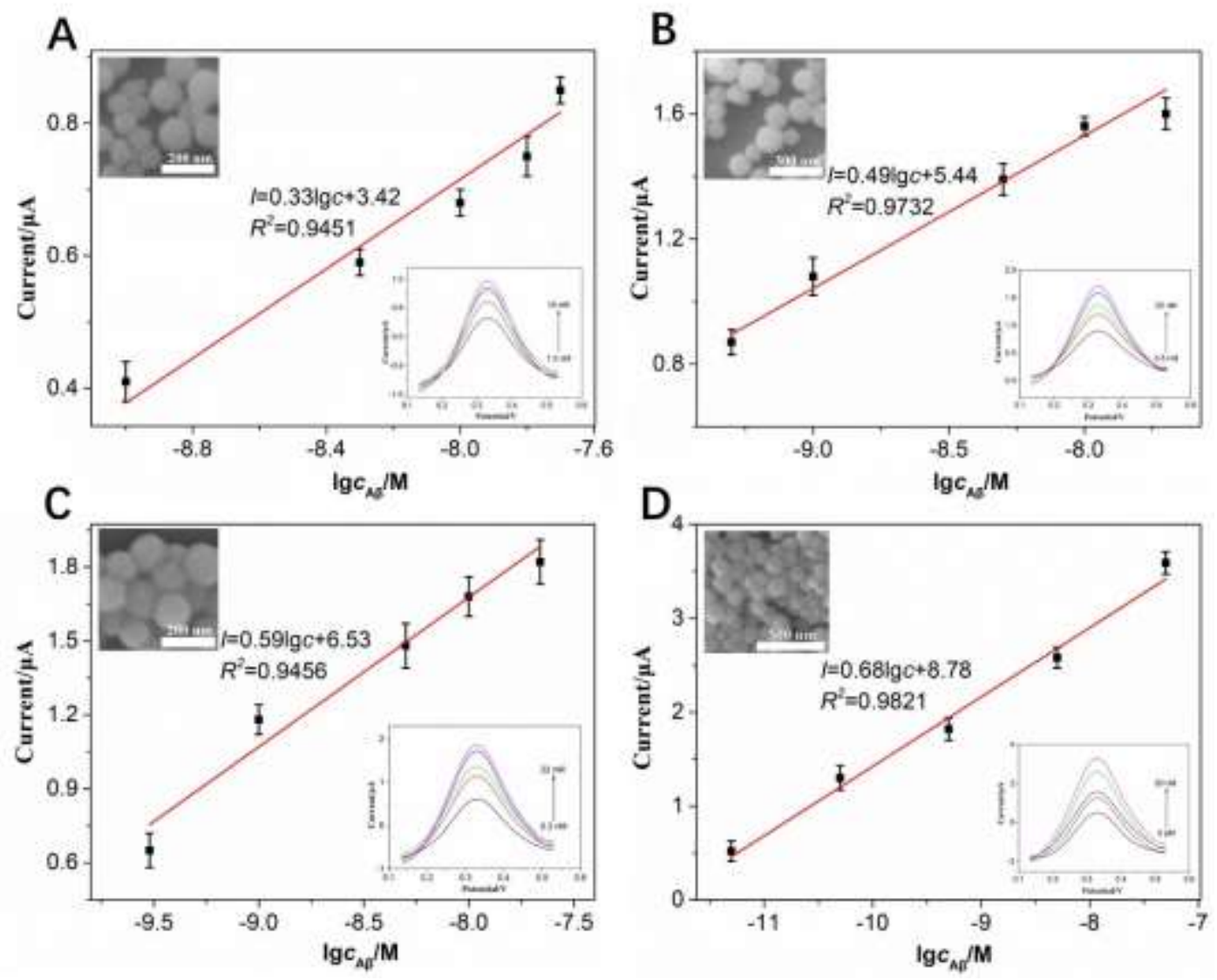

Figure S5. The calibration plots of (A-D) DPV peak current of the oPAD incubated with different bioconjugates: (A) $\mathrm{CeO}_{2}$, (B) $\mathrm{Co}-\mathrm{CeO}_{2}$, (C) $\mathrm{Cu}-\mathrm{CeO}_{2}$ and (D) $\mathrm{CuCo}-\mathrm{CeO}_{2}$. The insets are the corresponding DPV curves (lower right) and SEM images (upper left), respectively. The error bars represent the standard deviation of five repeated tests.

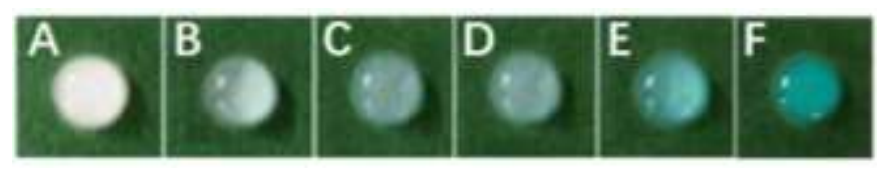

Figure S6. The TMB color changes of the oPAD incubated with different bioconjugates: (A) blank, (B) $\mathrm{CeO}_{2}$, (C) $\mathrm{Co}-\mathrm{CeO}_{2}$, (D) $\mathrm{Cu}-\mathrm{CeO}_{2}$, (E) $\mathrm{CuCo}-\mathrm{CeO}_{2}$ and (F) $\mathrm{CuCo}-\mathrm{CeO}_{2}-\mathrm{Pd}$. 

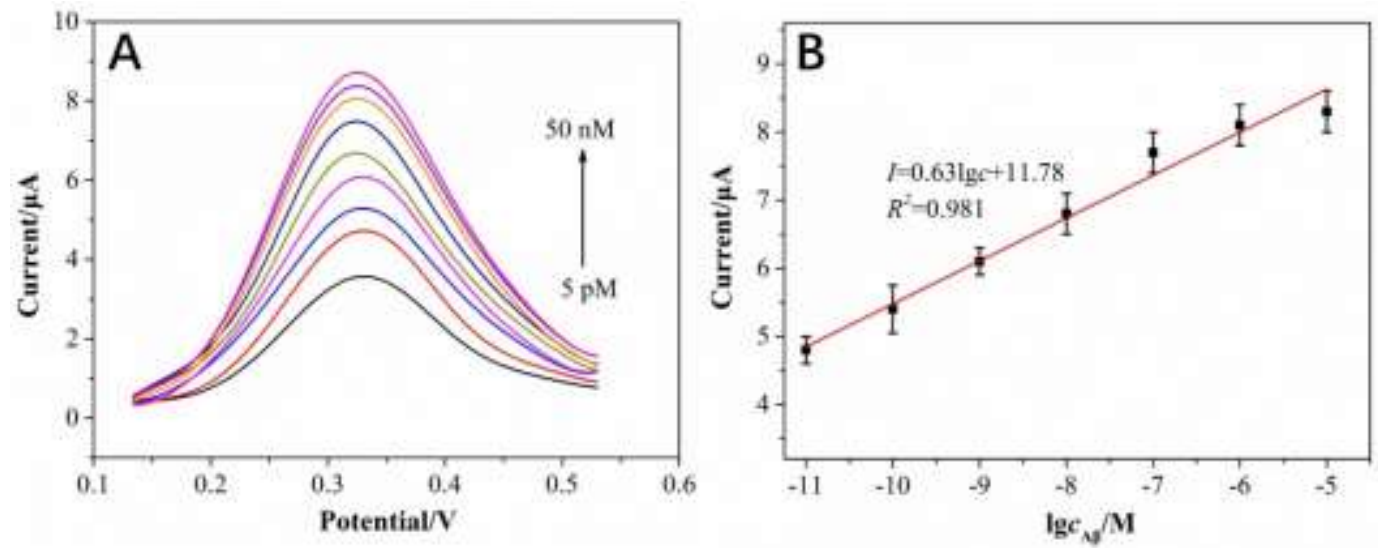

Figure S7. (A) DPV responses of the oPAD incubated with various concentrations of A $\beta$ (5 pM-50 nM) in human serum. (B) The calibration curve for the logarithm of DPV peak current versus $A \beta$ concentration $(5 \mathrm{pM}-50 \mathrm{nM})$.

\section{Comparison of the Proposed OPAD with Different Nanomaterials}

Table S1. Comparison of the proposed oPAD with different nanomaterials for detecting A $\beta$ proteins.

\begin{tabular}{ccc}
\hline Nanomaterials & Linear range & Detection limit \\
\hline $\mathrm{CeO}_{2}$ & $1 \mathrm{nM}-18 \mathrm{nM}$ & $0.3 \mathrm{nM}$ \\
$\mathrm{Co}-\mathrm{CeO}_{2}$ & $0.5 \mathrm{nM}-20 \mathrm{nM}$ & $0.12 \mathrm{nM}$ \\
$\mathrm{Cu}-\mathrm{CeO}_{2}$ & $0.3 \mathrm{nM}-22 \mathrm{nM}$ & $0.08 \mathrm{nM}$ \\
$\mathrm{CuCo}-\mathrm{CeO}_{2}$ & $5.0 \mathrm{pM}-50 \mathrm{nM}$ & $1.85 \mathrm{pM}$ \\
$\mathrm{CuCo}-\mathrm{CeO}_{2}-\mathrm{Pd}$ & $1.0 \mathrm{pM}-100 \mathrm{nM}$ & $0.05 \mathrm{pM}$ \\
\hline
\end{tabular}


Comparison of the Proposed OPAD with Other Techniques

Table S2. Comparison of the proposed oPAD with other techniques for detecting A proteins.

\begin{tabular}{llllc}
\hline Method & Materials & Linear range & Detection limit & Reference \\
\hline Fluorescence & Cu-BTC/Tb & $1-550 \mathrm{nM}$ & $0.3 \mathrm{nM}$ & 11 \\
Electrochem- & Ruthenium- & $0.2-1.7 \mathrm{ng} / \mathrm{mL}$ & $11.28 \mathrm{pg} / \mathrm{mL}$ & 12 \\
iluminescence & Labeled 3D6 & & & \\
ELISA & Monoclonal antibodies & $12.5-200 \mathrm{pg} / \mathrm{mL}$ & $10.7 \mathrm{pg} / \mathrm{mL}$ & 13 \\
LSPR & Au NPs/ApoE4 & $10 \mathrm{pM}-100 \mu \mathrm{M}$ & $1.5 \mathrm{pM}$ & 14 \\
Electrochemistry & Peptide-Fc probe & $480 \mathrm{pM}-12 \mathrm{nM}$ & $240 \mathrm{pM}$ & 15 \\
Electrochemistry & CuCo-CeO $2-\mathrm{Pd}$ & $1.0 \mathrm{pM}-100 \mathrm{nM}$ & $0.05 \mathrm{pM}$ & this work \\
\hline
\end{tabular}

Real Samples Analysis Performance

Table S3. The analysis of A $\beta$ in aCSF by using the proposed oPAD.

\begin{tabular}{lllll}
\hline Sample No. & Added & Found & Recovery & RSD \\
& $(\mathbf{n M})$ & $(\mathbf{n M})$ & $(\boldsymbol{\%})$ & $(\boldsymbol{\%})$ \\
\hline $\mathbf{1}$ & 0.001 & 0.00102 & 102 & 4.15 \\
$\mathbf{2}$ & 0.01 & 0.0099 & 99 & 3.62 \\
$\mathbf{3}$ & 1.0 & 0.992 & 99.2 & 2.54 \\
$\mathbf{4}$ & 10 & 10.05 & 100.5 & 1.63 \\
$\mathbf{5}$ & 100 & 99.89 & 99.89 & 1.02 \\
\hline
\end{tabular}




\section{REFERENCES}

(1) Xia, N.; Wang, X.; Zhou, B.; Wu, Y.; Mao, W.; Liu, L. Electrochemical Detection of Amyloid- $\beta$ Oligomers Based on the Signal Amplification of a Network of Silver Nanoparticles. ACS Appl. Mater. Interfaces 2016, 8, 19303-19311.

(2) Rushworth, J.; Ahmed, A.; Griffiths, H.; Pollock, N.; Hooper, N.; Millner, P. A LabelFree Electrical Impedimetric Biosensor for the Specific Detection of Alzheimer's AmyloidBeta Oligomers. Biosens. Bioelectron. 2014, 56, 83-90.

(3) Laurén, J.; Gimbel, D. A.; Nygaard, H. B.; Gilbert, J. W.; Strittmatter, S. M. Cellular Prion Protein Mediates Impairment of Synaptic Plasticity by Amyloid- $\beta$ Oligomers. Nature 2009, 457, 1128-1132.

(4) Wang, F.; Li, W.; Feng, X. L.; Liu, D. P.; Zhang, Y. Decoration of Pt on Cu/Co DoubleDoped $\mathrm{CeO}_{2}$ Nanospheres and Their Greatly Enhanced Catalytic Activity. Chem. Sci. 2016, 7 , $1867-1873$.

(5) Wu, Z.; Li, M.; Howe, J.; Meyer, H. M.; Overbury, S. H. Probing Defect Sites on $\mathrm{CeO}_{2}$ Nanocrystals with Well-Defined Surface Planes by Raman Spectroscopy and $\mathrm{O}_{2}$ Adsorption. Langmuir 2010, 26, 16595-16606.

(6) López, J. M.; Arenal, R.; Puértolas, B.; Mayoral, A.; Taylor, S. H.; Solsona, B.; García, T. $\mathrm{Au}$ Seposited on $\mathrm{CeO}_{2}$ Prepared by a Nanocasting Route: A High Activity Catalyst for $\mathrm{CO}$ Oxidation. J. Catal. 2014, 317, 167-175.

(7) Choudhury, B.; Choudhury, A. Lattice Distortion and Corresponding Changes in Optical Properties of $\mathrm{CeO}_{2}$ Nanoparticles on Nd Doping. Curr. Appl. Phys. 2013, 13, 217-223. 
(8) Yang, Z. H.; Ren, S. H.; Zhuo, Y.; Yuan, R.; Chai, Y. Q. Cu/Mn Double-Doped $\mathrm{CeO}_{2}$ Nanocomposites as Signal Tags and Signal Amplifiers for Sensitive Electrochemical Detection of Procalcitonin. Anal. Chem. 2017, 89, 13349-13356.

(9) Mehta P. D.; Pirttilä T.; Mehta S. P.; Sersen E. A.; Aisen P. S.; Wisniewski H, M. Plasma and Cerebrospinal Fluid Levels of Amyloid $\beta$ Proteins 1-40 and 1-42 in Alzheimer Disease. Arch. Neurol. 2000, 57, 100-105.

(10) Sun, L. P.; Zhong, Y.; Gui, J.; Wang, X. W.; Zhuang, X. R.; Weng, J. A Hydrogel Biosensor for High Selective and Sensitive Detection of Amyloid-beta Oligomers. Int. J. Nanomed. 2018, 13, 843-856.

(11) Liu, B. X.; Shen, H. H.; Hao, Y. Q.; Zhu, X.; Li, S. Z.; Huang, Y. K.; Qu, P.; Xu, M. T. Lanthanide Functionalized Metal-Organic Coordination Polymer: Toward Novel Turn-On Fluorescent Sensing of Amyloid $\beta$-Peptide. Anal. Chem. 2018, 90, 12449-12455.

(12) Bittner, T.; Zetterberg, H.; Teunissen, E.; Ostlund Jr, R.; Militello, M.; Andreasson, U.; Hubeek, I.; Gibson, D.; Chu, D.; Eichenlaub, U.; Heiss, P.; Kobold, U.; Leinenbach, A.; Madin, K.; Manuilova, E.; Rabe, C.; Blennow, K. Technical Performance of a Novel, Fully Automated Electrochemiluminescence Immunoassay for the Quantitation of $\beta$-Amyloid (142) in Human Cerebrospinal Fluid. Alzheimers Dement. 2016, 12, 517-526.

(13) Kim, J. A.; Kim, M.; Kang, S. M.; Lim, K. T.; Kim, T. S.; Kang, J. Y. Magnetic Bead Droplet Immunoassay of Oligomer Amyloid $\beta$ for the Diagnosis of Alzheimer's Disease Using Micro-Pillars to Enhance the Stability of the Oil-Water Interface. Biosens. Bioelectron. 2015, 67, 724-732.

(14) Kang, M. K.; Lee, J.; Nguyen, A. H.; Sim, S. J. Label-Free Detection of ApoE4-Mediated $\beta$-Amyloid Aggregation on Single Nanoparticle Uncovering Alzheimer's Disease. Biosens. Bioelectron. 2015, 72, 197-204. 
(15) Li, H.; Cao, Y.; Wu, X. L.; Ye, Z. H.; Li, G. X. Peptide-Based Electrochemical Biosensor for Amyloid $\beta$ 1-42 Soluble Oligomer Assay. Talanta 2012, 93, 358-363. 